\title{
Predicting maternal aspirations for their children's education: The role of parental and child characteristics
}

\author{
Edward M. Sosu
}

School of Education, University of Strathclyde, Humanities, Arts \& Social Sciences, Lord Hope Building, G40LT, Glasgow, UK.

Email: edward.sosu@strath.ac.uk

Tel: +44 (0)1414448063

\begin{abstract}
The current study investigates the nature of maternal educational aspirations and factors that influence mother's aspirations for their children's education in the preschool years. Data were drawn from the Growing Up in Scotland survey $(N=1999)$. Findings showed that while majority of mothers (74\%) held high educational aspirations for their children, a substantial proportion (12.4\%) only aspired for their children to attain high school education and below. Consistent with hypothesis of the transactional model (Sameroff and Mackenzie 2013) used in this study, both parental (socioeconomic status, household size and age) and child characteristics (birth order, gender and conduct problems) significantly predicted mothers' aspirations for their children's education. The educational and policy implications of these findings are discussed.
\end{abstract}

Keywords: parental educational aspirations; preschool children; transactional model; social and cultural reproduction theory; Growing Up in Scotland 


\section{Introduction}

Parental aspirations for their children's education is a key parental variable that has received considerable attention in recent years. It represents the level of education that parents would like their children to attain ${ }^{1}$ (Spera et al. 2009). Research suggests that such aspirations are persistent over time (Raleigh and Kao 2010) and positively correlated with various educational outcomes for children (e.g., Chiapa et al. 2012; Gregg and Washbrook 2009; Schoon et al. 2007; Villiger et al. 2014). A meta-analysis of parental involvement variables concluded that parental aspirations was the strongest predictor of children's school grades, and is therefore one of the most crucial component of parental involvement (Jeynes 2007). Several pathways account for how parental aspirations influence children's educational outcomes (see Yamamoto and Holloway 2010 for a review). Firstly, aspirations affect the resources parents devote to supporting their children's education. Those with higher aspirations devote more time (e.g., helping with homework) and resources to school related activities (Spera 2006; Sy and Schulenberg 2005). Secondly, parental aspirations have an influence on children's own academic expectations and motivation and these in turn have an impact on their achievement (Benner and Mistry 2007; Kirk et al. 2011; Rutchick et al. 2009; Villiger et al. 2014). In a nutshell, aspirations drive parental decisions, thereby creating a “self-fulfilling prophecy” in terms of children's educational achievement (Wentzel 1998). The perceived importance of aspirations has led to various government policies aimed at involving and helping parents develop higher aspirations for their children's education (e.g., Department for Children, Schools and Families 2007; Scottish Executive 2006).

\footnotetext{
${ }^{1}$ Although aspirations and expectations have sometimes been used interchangeably (e.g., Fan and Chen 2001; Juang et al. 2002), other writers have sought to distinguish between these terminologies (Gorard et al. 2012; Oketch et al. 2012). At the preschool age, parental aspirations and expectations may be indistinguishable (Goldenberg 2001).
} 
While interest in parental educational aspirations has generated several research and policy outcomes, the question of what influences differing aspirations has received limited attention and remains unclear (Rutchick et al. 2009). Understanding predictors of parental aspirations is crucial for identifying causes of lower aspirations and designing appropriate interventions to help parents develop higher educational goals for their children. Further, of the few existing studies, the majority are based on samples of parents whose children are in primary or high school and not on parents of pre-school children. Focusing on parents of older children brings into question the direction of the relationship between parental aspirations and children's educational outcomes. At this stage it is not clear whether it is the child's educational performance that shapes parents aspirations or vice versa, or whether the relationship is bidirectional. Additionally, at the preschool stage parental educational aspirations reflect hopes about future potentials which are communicated to their children in various ways. Thus, it can be argued that aspirations may be more important at this early age when they are beginning to form perceptions about themselves than in later years. The aim of the current study is to examine predictors of educational aspirations of parents whose children are in preschool. Specifically, this study focuses on aspirations of mothers and references to parental aspirations should be understood within this context.

\section{Determinants of Maternal Educational Aspirations: Theoretical Perspectives}

Most investigations into the determinants of parental educational aspirations for their children tend to focus on discrete factors such as parental socioeconomic status, ethnicity, child's gender, and academic performance of the child (e.g., Goldenberg et al. 2001; Oketch et al. 2012; Spera et al. 2009). With the exception of one study (Vryonides and Giouvias 2012), most studies reviewed did not provide any theoretical framework to account for the 
determinants of parental aspirations. Thus, where multiple predictors have been used by researchers, the focus was usually on a single factor while treating other factors as confounders (e.g., Oketch et al. 2012; Zhang et al. 2007). This absence of comprehensive theoretical lens makes it difficult to propose meaningful explanations without resorting to individual factors. Within this study, two overarching theoretical perspectives are considered. These are Bourdieu's social and cultural reproduction theory, and Sameroff's transactional model.

\subsection{Social and Cultural Reproduction Theory}

Bourdieu's social and cultural reproduction theory attempts to explain why inequalities persist and how it is reproduced in societies (Bourdieu 1977a; 1986a; Bourdieu and Passeron 1990). The theory posits that socialisation involves social groups unconsciously communicating the boundaries of the opportunities available to members of their particular communities. These opportunities and their boundaries are internalised by community members and in turn dictates how they act, think and live. As a result, the differences that we see in the values, dispositions and aspirations between social groups are due to differences in socialisation about what is possible within their communities. In a nutshell, the process of socialisation preserves the status quo and leads to reproduction of inequalities. The extent to which the theory explains parental aspirations is best understood through Bourdieu's concepts of habitus and capital (cultural and social). These are the key enablers of reproduction.

Habitus denotes sets of attitudes, values or dispositions (Bourdieu 1977a; 1977b). It is argued that each social group adopt its own characteristic habitus but the dominant habitus tends to 
be those held by advantaged groups. An example of dominant habitus is a positive attitude towards education (Bourdieu 1977a). According to Bourdieu (1977b), the habitus is a product of unconscious socialisation in early childhood and integrates experiences that are statistically common to members of one's social group. Social groups internalise their 'statistical fate', set aspirations and act in accordance with perceived outcomes (DiMaggio 1979). In this respect, social background generates unconscious expectations that are based on one's evaluation of the destiny of "people like us" (Nash 1990). This unconscious calculation of objective probabilities often leads members of lower socioeconomic groups to opt out of educational competition (Bourdieu 1977a\&b). Thus, aspirations for a child's education will be couched with reference to parents' perceptions of what is possible within their particular socioeconomic group.

Cultural Capital defines an individual's familiarity with the dominant culture in a particular society (Bourdieu 1977a) and can exist in three different forms - an embodied state (e.g., disposition of the mind), objectified state (e.g., books, pictures), and institutionalised state (e.g., educational qualification) (Bourdieu 1986b). Parents from higher socioeconomic backgrounds are familiar with the advantages of the dominant cultural capital, such as, high educational credentials. They will therefore be more inclined to set higher educational aspirations for their children knowing very well that such qualifications will help their children secure a dominant position within the society. Social Capital on the other hand relates to networks of relationships and social connections which individuals can mobilise to achieve particular goals (Bourdieu 1986b). Those from dominant classes tend to possess more dense social capital as a result of mutual acquaintances, kingship relations, schools attended and membership of select groups (Bourdieu 1986b). Parents from 
socioeconomically advantaged groups will therefore set higher educational goals for their children knowing that they will be able to draw on networks and social connections to help their children achieve such goals. In summary, parental aspirations for their children's education are influenced by their habitus, cultural and social capital.

In as much as this theoretical perspective is useful in explaining the influence of socioeconomic factors on parental aspirations, it is not without its limitations. Several authors have pointed to the absence of clarity in most of Bourdieu's concepts and difficulties in subjecting these to empirical verification (e.g., DiMaggio 1979; Sullivan 2002; Nash 1990; Dika and Singh, 2002). Most importantly, the theory is limited by its inability to account for the range of factors that influence parental aspirations. For instance, empirical studies suggests a child's gender as well as academic performance can have significant influences on parental aspirations (see e.g., Spera et al. 2009). These and other factors are not easily captured through a socioeconomic lens.

\subsection{Transactional Model}

As a result of the latter limitation of the reproduction theory discussed above, the Transactional Model (Sameroff 2009; Sameroff and Mackenzie 2003) was adopted as a framework to understand the predictors of maternal educational aspirations for their preschool children within the current study. The transactional model proposes that an individual's disposition is a product of ongoing interaction between the individual and experiences provided by the environment. Thus, the causes of a disposition or behaviour should not be understood as only residing in the individual, but as a combination of both the individual's characteristics and characteristics of his or her social context. A singular focus 
on the characteristics of the individual in predicting their disposition will therefore be misleading. Empirical support for this model has been demonstrated through reciprocal influences of child and parent characteristics on children's subsequent behaviours (e.g., Fanti et al. 2008; Pomerantz and Eaton 2001; Sutherland and Oswald, 2005). Extrapolated to parental aspirations, it is argued that parental aspirations are a result of both the characteristics of the parent and characteristics of the context, that is, the child. In other words, it is not only the parents' own circumstances and experiences that shape their aspirations but also characteristics displayed by the child helps inform those aspirations. These characteristic are the focus of discussion in this section of the paper.

\section{Role of Parental and Child Characteristics}

\subsection{Parental Characteristics}

Empirical studies suggest that there are certain characteristics of a parent that influences whether or not the parent will have higher or lower aspirations for a child's education. Among these are parental socioeconomic status, ethnicity and age.

3.1.1 Mother's Socioeconomic status: Job status, Income and Education: It is generally proposed that parents transmit their socioeconomic status (SES) to their children through aspirations (Oketch et al. 2012; Bourdieu 1977b). Although most parents have the desire for their children to attain higher levels of formal schooling (e.g., Goldenberg et al. 2001; Spera et al. 2009), parents from higher socioeconomic backgrounds tend to hold higher educational aspirations compared with those from lower socioeconomic backgrounds (Oketch et al. 2012; Schoon et al. 2007; Zhang et al. 2007). For instance, Gregg and Washbrook (2009) found that while $81 \%$ of the richest mothers reported that they hoped their 9-year-old will go to university, only $37 \%$ of poorest mothers held similar aspirations. 
SES is conceptualised in two main ways within the literature. These include a unidimensional proposition based solely on job status and a multidimensional conceptualisation which encompasses job status, income and education (Braveman et al. 2005). The latter more comprehensive measure of SES is adopted in the current study. Job status influences parental aspirations through networks and role models. Parents in higher status jobs generally have more dense and educationally relevant social networks that they can draw on to support their children's education and this gives them the confidence to set higher goals. Those from lower job status on the other hand do not have educationally relevant social capital to enable them set higher aspirations (Bourdieu 1986b; Esping-Andersen 2004). Additionally, parents may calibrate their expectations based on experiences from their own environment. Thus, those lower down the social ladder might not have the confidence to hold higher aspirations in the absence of role models in their communities (Bourdieu 1977b; Breen and Goldthorpe, 1997). With respect to income, it is argued that parents tend to set educational aspirations for their children based on their evaluation of cost and opportunities. Mothers with higher income may believe that they have the resources to help their children achieve higher levels of education and as a result tend to set higher educational aspirations for their children (Oketch et al. 2012). However, those with lower income based on rational calculation tend to set lower goals in line with their financial abilities (Schoon et al. 2007)

Finally, parental education is one of the most consistent SES predictors of aspirations for children's education. Parents with higher levels of education tend to set higher educational aspirations for their children in comparison to those with lower levels of education (e.g., Chowdry et al. 2010; Spera et al. 2009; Zhang et al. 2007). This is because education may 
serve as a proxy for parental resources as well as indicative of parents' ability to help their children with school work. Additionally, parent's own experiences and successes in education may serve as a catalyst to set higher goals for their children. Those parents who have experienced failure may be pessimistic regarding its prospects (Räty 2003) and therefore set lower targets taking into account their own shortcomings (e.g., Bourdieu 1977a).

\subsubsection{Mother's Ethnicity: It has been suggested that ethnicity (at least within Western} societies) is an important predictor of parental aspirations although this relationship is not straight forward. Several studies have found that parents from "other ethnic groups" are more likely to set higher educational aspirations for their children compared to their white counterparts (Chowdry et al. 2010; Wentzel 1998). The claim is that parents from ethnic minority groups tend to place high value on education because they see education as a means for upward social mobility (Goldenberg et al. 2001). Other studies have however found inconclusive evidence for the effect of ethnicity on parental aspirations if ethnicity is more finely defined. Spera et al. (2009) for instance found that while Asian American parents had higher educational aspirations than all other ethnic groups in their study, both AfricanAmerican and Hispanic Americans had lower aspirations than their white peers. There is also evidence to suggest that differences exist between immigrant and native-born minorities (Raleigh and Kao 2010). Further, the effect of ethnicity on aspirations disappears when parental education and children's academic performance are accounted for (Spera et al. 2009). Parental ethnicity was not examined in this study due to the small sample size of parents who were categorised as belonging to 'other ethnic groups' in the data ${ }^{2}$.

\footnotetext{
${ }^{2}$ The data used for this study classified participants into 'white' versus 'other ethnic groups'. The sample size for participants in the 'other ethnic group' category was very small and it was not possible to decompose it into distinctive groups and explore differences between various ethnic groups. Using a data set that allows
} 
3.1.3 Maternal age: Although not previously explored, one parental variable with potential to influence aspirations is age. Result from various studies suggest positive relationships between increased maternal age and educational achievement of children, reduced truant behaviour, more knowledgeable parenting and stable home environment (Fergusson and Woodward 1999; Sutcliffe et al. 2012). Generally, older mothers are those who delay childbirth in order to pursue educational and career development (Fergusson and Woodward 1999), and are therefore more likely to be in a high SES group, have more stable home environments, and be ambitious. It is therefore reasonable to hypothesise that these older mothers would have equally ambitious educational aspirations for their children. The role of maternal age on mother's educational aspiration for their children was therefore investigated in the current study.

\subsection{Child characteristics}

Consistent with the transactional model, several child level characteristics have been found to influence parental educational decisions including aspirations. Of particular interest are children's academic achievement, gender, emotional and behavioural dispositions, and birth order.

3.2.1 Child's Academic Achievement: There is evidence to suggest that parental aspirations for their children's education are to a large extent influenced by a child's academic performance. Parents hold higher educational aspirations for high achieving children while tending to hold lower aspirations for those not doing well at school (Kirk et al. 2011; Goldenberg et al. 2001; Villiger et al., 2014; Zhang et al. 2007). Further, just the belief about

comparison between different groups is important in making more realistic judgements about the impact of ethnicity on parental aspirations. 
how the child is faring academically, even if not rooted in reality, can influence educational aspirations for the child (Oketch et al. 2012; Spera et al. 2009). These findings suggest a reversal of the causal direction between parental aspirations and children's attainment, or a potential bidirectional relationship. Within the current study, measures of academic achievements were not available as the children were just starting school. It is hypothesised that barring the absence of an objective measure of a child's educational potential, parents may use other available characteristics in making heuristic judgements of where they hope their child will reach on the educational ladder. In other words, findings from this study should circumvent the confounding relationship between a child's academic performance and parental aspirations and therefore give insight into unique influences on parental aspirations. It is however important to note that while parental educational aspirations are relatively stable overtime for younger children (Goldenberg et al. 2001), parental expectations tend to be mediated by the child's academic performance as the child gets older (Englund et al. 2004; Goldenberg et al. 2001).

3.2.2 Child's Gender: The claim that the gender of a child influences parental aspirations for their education has produced mixed results. Studies within the UK have shown that mothers tend to have higher educational aspirations for daughters than sons (Chowdry et al. 2010; Schoon et al. 2007). Similar optimism for girls have been found among Hispanic and white parents in the US (Raleigh and Kao 2010). Studies in Japan (Lee 2010) and China (Zhang et al. 2007) on the other hand found that mothers held higher educational aspirations for sons than daughters although this was largely dependent on the mothers' education and the extent to which they hold traditional values. Thus, more educated mothers tend to hold less traditional gender norms that are linked to lowered educational aspirations for girls. A study 
by Oketch and colleagues (2012) in Kenya however found no association between parental aspiration for their children's education and the gender of the child. Studies in the US also show no association between gender and parental aspirations for black and Asian parents (Raleigh and Kao 2010). The above suggests that complex socio-cultural and economic factors may be accounting for differences in aspirations for girls and boys. For instance, there is consistent evidence within the UK that participation in higher education is greater for girls than boys (e.g., Scottish Funding Council 2013). Thus, parental aspirations for each gender may be influenced by knowledge of how the different gender groups engage with education within the society. Parents may therefore calibrate their aspirations using existing information on differential gender participation in higher education. Alternatively, it is likely that cultural preferences for one gender over another, rooted in perceived social or economic returns for the family, may influence the aspirations that mothers set for their children (e.g., Buchmann and Hannum 2001; Zhang et al. 2007).

\subsubsection{Child's Emotional and Behavioural Disposition: A key area of a child characteristic} known to significantly influence the relationship between children and their caregivers is emotional and behavioural difficulties (EBD). Evidence suggests that child behaviour problems have an influence on parental behaviours (Pettit et al. 2001). While the effect of child EBD on parental aspirations has been largely neglected, the only available study shows that, in comparison to a typically developing child, parents hold significantly lower educational aspirations for a child identified as having behaviour problems. This reduced aspirations in response to behaviours exhibited by the child subsequently resulted in lower academic achievement (Rutchick et al. 2009). It is argued that parents believe their children's ability to succeed academically will be hindered by problem behaviour and therefore adjust 
their aspirations accordingly (Rutchick et al. 2009). In other words, child behaviour problems may have biasing effects that cause parents to have reduced aspirations. The current study extends Rutchick et al.'s (2009) work by exploring the influence of other dimensions of EBDs (conduct problems, hyperactivity, emotional symptoms, peer relations, pro-social behaviour (Goodman 1997)) on parental aspirations. Empirical findings suggest that these behavioural problems lead to difficulties in adjustment and can induce parent-child interactive stress (e.g., Theule et al. 2013; Gini 2008; McLeod and Kaiser 2004; Masten et al. 2005). Parents may therefore have lowered educational aspirations for children displaying behavioural difficulties based on an assessment of the child's ability to succeed in a school environment.

\subsubsection{Child's Birth order and Family Size: Recent studies on the role of birth-order}

differences on child outcomes suggest that higher birth order (those who are born later) leads to worse outcomes (e.g., Booth and Kee 2009; Price 2008) although this may not always be the case (e.g., Powell and Steelman, 1995). Despite these effects of birth order, studies have not yet explored its influence on parental educational aspirations. One of the key arguments used to explain the positive effect for first born children is the resource dilution hypothesis (ibid). This proposes that first born children receive greater financial and psychological resource endowments because they get to be an only child during the early years of life in comparison to subsequent children who have to share parental resources (Price 2008).

Drawing on the above discussions, it can be argued that there may be birth order effects on parental educational aspirations for their children. This is because parents generally want the best for their child including the highest level of education. However, parents will 'anchor' aspirations for subsequent children on the performance of the first born child (Tversky and 
Kahneman 1974). In other words, they will have equally high educational aspirations for subsequent children if the first born shows high academic achievement. However, if the achievements of the first born child does not meet expected aspirations, then even though parents might have high educational hopes for the second born, these aspirations will be anchored around the achievement of the first born and will not be as high as they were for the first born.

Birth order is usually confounded with family size. Like birth order, family size can equally influence parental aspirations through resource dilution. Parents with smaller family sizes are likely to have more financial resources and as a result set higher educational aspirations and vice versa. A challenge therefore for estimating birth order effect is that it is closely associated with family size. First born children have higher probability of coming from a smaller family size than those born later in the birth order (Booth and Kee 2009). Within the current study, the effect of birth order was evaluated taking into account family size. Although birth order relates to child characteristics while family size to parental characteristics, the two are discussed together because of their close relationship.

\section{The Current Study}

To recap, very few studies have comprehensively examined predictors of parental aspirations for preschool children. Drawing on the transactional model and existing empirical studies, it is argued that parental aspirations are stratified by both parental and child characteristics. The current study explores the role played by these parental and child characteristics in shaping maternal educational aspirations for their pre-school children. Specifically, the study addresses two primary research questions: 
a) What is the nature of maternal aspirations for preschool children?

b) To what extent does parental and child level characteristics influence maternal aspirations for their children's education?

\section{Methods}

\subsection{Data and Participants}

The current study was undertaken using the Growing Up in Scotland Survey (GUS) data. GUS is a national longitudinal survey which explores a range of topics related to children's development. Due to its comprehensive coverage of a range of issues, it provides the most appropriate opportunity for exploring multivariate relationships of interest to the current study. Additionally, it is the only known national survey in Scotland that includes questions on parental educational aspiration for preschool children. Two separate cohorts are followed annually with the GUS survey. These are a Birth Cohort representing babies who were 10.5 months old at time of the first sweep in 2005, and a Child Cohort which consists of toddlers aged 34.5 months at time of first sweep in 2005. While the Birth Cohort is still ongoing, the last follow-up of the Child Cohort (Sweep 4) was in 2008-2009. The sample for the survey was based on the UK's Child Benefit Records. A multi-stage stratified random sampling technique of all eligible children within a cohort year was used in selecting participants to ensure a nationally representative sample. Data were obtained using a face-to-face interview of the child's main carer (mostly the child's mother). A detailed description of the sampling procedure and method of data collection is published in the official user guide (Bradshaw et al. 2010). 
For the purposes of the current study, data from the Sweep 4 Child Cohort survey obtained between April 2008 and May 2009 was used. This was chosen because it was only within this sweep that all participants were asked about their aspirations for their children's education. The original sample size was 2200 , representing a $90 \%$ response rate of all eligible participants. Data from 1999 samples were considered suitable for the current study. The remaining were excluded for a variety of reasons. These included participants who did not provide a response to the question used to measure maternal aspirations $(n=23)$, who stated that they did not mind what level of education their children reached $(n=122)$, and those who were fathers $(n=44)$ or other persons rather than the child's mother $(n=12)$. Since maternal aspirations were investigated, it was reasoned that deletion of other respondents will allow for consistency in claims made from findings. The cohort children were aged between 5-6 years.

\subsection{Dependent Variable: Maternal Educational Aspirations}

The dependent variable, maternal aspirations for their children's education, was measured by asking participants to respond to the question: "Even though it may be a long way off, how far in school, further or higher education would you like childname to go?" Responses ranged from Standard Grades (Lower Secondary [1]), Higher (Upper Secondary [2]), College ${ }^{3}$ below degree [3], Degree [4], Masters, PhD, Medical, or Other Advanced Degree [5], and I don't really mind [6]. Since a degree qualification is seen as a crucial marker in educational attainment (Reynolds and Pemberton 2001), the categories 4 and 5 were combined. This was also consistent with approaches adopted in previous studies (e.g., Raleigh and Kao 2010). Additionally, responses from categories 1 and 2 were combined due to the very small

\footnotetext{
${ }^{3}$ A college level certificate in the UK is usually offered on programmes which are at a level below a university bachelor degree.
} 
response on category $1(n=47)$ and the closeness between these two categories. As indicated earlier, responses on the last category (I don't really mind - 6) were deleted from analysis. Thus, a polytomous ordinal dependent measure of maternal aspirations with three levels $(1=$ High School and below, 2=College, 3=Degree and above) was created.

\subsection{Independent variables}

Both parental and child characteristics were specified as predictors of maternal educational aspirations.

\subsubsection{Parental Characteristics}

The parental characteristics included in the analysis were socioeconomic status (job status, household income, and education), maternal age and family size (Table 1). Socioeconomic Status (SES) within the data set was based on job status. Since this has limited utility, SES was reconceptualised as a multidimensional construct encompassing job status, household income and maternal education. Job status (referred to as SES in the GUS data set) was a derived variable based on employment relations (Office of National Statistics 2005). This classifies individuals using the characteristics of their job such as career prospects, autonomy, mode of payments, and period of notice. The GUS dataset includes six categories of job status (Table 1) with higher values indicating higher status. Job status was treated as a continuous variable in the multivariate analysis due to the number of categories. Household income was a derived variable on a scale of 1-17 based on actual household income. These scales represent specific annual income bands (from 1 - less than $£ 3,999$ to $17-56,000$ or more). The original measure of Maternal Education was in six categories (degree, vocational, higher grade, standard grade, other, no qualification). These categories were collapsed into four groups (degree, vocational, higher/standard grade, no qualification). The categories 
higher and standard grade was combined to ensure consistency in approach, that is, following the same approach in categorising maternal aspirations. The 'other' category was also added to the higher/standard grade group as this had only 6 responses. Higher scores indicate higher educational attainment. Due to the number of categories, maternal education was treated as a continuous variable within the analysis.

Maternal Age within the data set was categorised into three age groups (20-29, 30-39, 40 and above). This corresponded to the age of mothers at the time of interview. Family size was measured using the total number of people (adults and children) in the household. This ranged from 2 to 12 people in a household.

\subsubsection{Child characteristics}

Child characteristics were gender, birth order, and emotional and behavioural difficulties (Table 1). Gender was dummy coded into male (1) and female (0). Birth order was a derived variable which represents whether the study child was mothers' first born or not. The responses were dummy coded into first born (1) and other children (0). Emotional and Behavioural Difficulties (EBD) within the GUS data were measured using Goodman's (1997) 25-item Strength and Difficulties Questionnaire. The questionnaire measures five dimensions of EBD: emotional symptoms, conduct problems, hyperactivity/inattention, peer relation problems and pro-social behaviour. Each dimension contains 5 items and scores can range from 0 to 10. A higher score for all dimensions except for pro-social behaviour indicates presence of EBD.

\subsection{Statistical Analysis}


The analysis proceeded in two phases. In the first phase, descriptive and bivariate analyses using chi-square tests and Analysis of Variance (ANOVA) were undertaken to explore the nature of parental educational aspirations as well as its relations with each of the hypothesised predictors. The aim of the bivariate analyses was to ensure that only predictors that have significant bivariate relationship with maternal educational aspirations are included in the multivariate analysis. In phase two, multivariate analyses using ordinal logistic regression was carried out to establish whether or not a systematic relationship exists between selected parental and child characteristics and the probability of parents having higher or lower educational aspirations for their pre-school children. This analytic technique is parsimonious and was chosen because the outcome variable, maternal aspirations, was categorical and ordinal. The assumptions of proportional odds underlying ordinal logistic regression were tested and met (see results section). Due to the nature of the sampling procedure used for the GUS survey, all analyses were carried out using cross-sectional weights to account for unequal probabilities of selection and non-response bias (Bradshaw et al. 2010).

\section{Results}

\subsection{Descriptive and Bivariate Analysis}

Descriptive statistics and results from bivariate analyses are presented in Table 1. The distribution of maternal aspiration shows that majority of mothers (74\%) aspired for their children to obtain a university degree and above. This suggests that mothers in Scotland generally have very high educational aspirations for their children. However, 13\% (about 1 in 7) of the mothers aspired for their children to go to college while 12.4\% (about 1 in 8) aspired for their children to attain high school education and below. 
With respect to parental characteristics, significant bivariate associations were found between mother's SES variables (job status, income and education) and educational aspirations for preschool children. Those with the highest job status (86.5\%) held higher aspirations for their children to attain a degree and above than those with the lowest job status (68.9\%). An exception to this trend is parents who belonged to the category "small employers and own account workers". This group, contrary to the general trend, held lower educational aspirations for university and above $(63.3 \%)$ in comparison to parents from other lower job status categories such as those who have never worked (68.9\%) and "lower supervisory and technical occupations" (69.6\%). Overall, the proportion of mothers aspiring for higher levels of education increases with increased levels of parental education. Mothers with university degrees $(89.6 \%)$ had higher aspirations for their children to obtain degree and above in comparison to mothers with no qualifications (57.1\%). Most mothers without qualifications or lower levels of qualifications aspired for their children to attain higher levels of education than their own. The final SES variable indicates that mothers who aspired for their children to acquire degree and above come from households with higher levels of average income per year (29000-31999) than those with aspirations for high school and below (20000-22999).

In addition to SES other parental characteristics such as maternal age and family size were significantly associated with maternal aspirations. Older mothers appear to set high 
educational aspirations for their children in comparison to younger mothers. Over $80 \%$ of mothers aged 40 and above aspired that their children will complete a degree compared with $73 \%$ and $69 \%$ of mothers aged $30-39$ and $20-29$ respectively. On average, mothers with higher educational aspirations appear to come from smaller families $(M=4.04, S D=1.04)$ than those with lower aspirations $(M=4.26, S D=1.13)$.

In terms of child characteristics, significant associations were found between all variables and maternal aspirations. With respect to the emotional and behavioural difficulties variables examined, mothers tended to have lower educational aspirations for children with higher scores on the difficulties scales and, and higher aspirations for those with higher scores on the pro-social behaviour scale. Although the average scores on emotional symptoms and hyperactivity/inattention were higher for children whose parents aspired for college education than for those who aspired for high school and below, these differences were not statistically significant. It is important to note that the average scores indicate very low levels of emotional and behavioural problems in the sample (see Goodman 1997). On the whole, mothers tended to have higher aspirations for first born children to complete university (78.9\%) as against those later in the birth order (69.7\%). While all parents had high aspirations for their children's education irrespective of gender, aspirations were higher for girls $(76.6 \%)$ to achieve university level education than for boys $(71.5 \%)$.

\subsection{Multivariate Analysis: Ordinal Logistic Regression Model}

All parental and child characteristics were specified to predict maternal educational aspiration

(Table 2). Results from analysis showed that the model was statistically significant $X^{2}$ (13, $\mathrm{N}=1990)=196.82, \mathrm{p}<.001$, and goodness-of-fit statistics (Pearson $\mathrm{X}^{2}$ and Deviance) indicate 
that the model was a good fit. The assumption of proportional odds (test of parallel lines) which proposes that explanatory variables have the same effects on the odds regardless of threshold was met $\mathrm{X}^{2}=8.86, \mathrm{p}=.78$. The pseudo R-Square (Nagelkerke $\mathrm{R}^{2}$ ) was .13 .

INSERT TABLE 2 HERE

As shown in Table 2, all parental variables made unique statistically significant contributions to maternal aspirations after controlling for other variables. Maternal SES variables (education, income and job status) had a significant effect on maternal aspirations, with maternal education being the most significant predictor. On the whole, the odds for mothers having higher educational aspirations for their children increases by 1.52 times (52\%) for each additional level of maternal education, 1.04 times (4\%) for each unit increase in household income, and by 1.11 times $(10.5 \%)$ for each unit increase in job status. With regards to Maternal age, older mothers (aged 40 and above) were more likely to have higher educational aspirations for their children than those in a younger age bracket $(20-29 ; 30-39)$. However, this difference was only significant for mothers in their 30s (from 30-39). This group was $31.6 \%$ less likely to have higher aspirations compared with those aged 40 and above. Translated in favour of older mothers, the findings suggest that older mothers are about $46 \%$ more likely to hold higher educational aspirations than younger mothers. Although mothers aged 20-29 had lower aspirations than those aged 40 and above, the difference in aspiration was not statistically significant. The size of the household which parents came from also influenced their educational aspirations for their children. The odds of 
parents having higher educational aspiration decreases by .89 times $(11 \%)$ for every unit increase in family size. In other words, having a small family increases the odds of mothers holding a higher educational aspiration for children.

With regards to child variables, the most significant predictor of maternal educational aspirations was the child's birth order. Mothers were 1.49 times (49\%) more likely to have higher aspirations for a first born child relative to other children in the birth order. This influence of birth order on maternal aspirations was significant irrespective of household size. The influence of gender on aspirations was also significant with mothers being 1.25 times (25\%) more likely to have higher educational aspirations for girls than for boys. Of all the emotional and behavioural difficulties variables, only conduct problems had an impact on maternal aspirations. For every unit increase on the conduct problem scale, mothers were .89 times (11\%) less likely to have higher educational aspirations for the child. Considering that the standard deviation for conduct problems was 1.52 and $\operatorname{Exp}(.90 * 1.52)=3.93$, a parent whose child scores $1 \mathrm{SD}$ above the mean score on the conduct problems scale is 3.93 times less likely to have higher educational aspirations for the child. Emotional symptoms, hyperactivity/inattention, peer problems, pro-social behaviour did not have any impact on maternal aspirations.

\section{Discussion}

The aim of the current study was to explore the nature of maternal aspirations for their preschool children's education and the predictors of these aspirations. On the whole, majority of mothers in this study held high educational aspirations for their preschool children and in some cases, aspirations that were higher than their own qualifications. Thus, for most parents 
there is no 'aspirational crisis' but rather how to sustain those aspirations over time or turn them into reality. Figures in Scotland indicate that between the period 2006 to 2012, only about $28 \%$ of those aged between 16 and 30 years enter a degree programme every year (Scottish Funding Council 2013). This compared with a maternal educational aspiration for degree level education of $74 \%$ suggests a large gap between aspirations and actual participation rates. As noted in previous studies (e.g., Goldenberg et al. 2001; Kirk et al. 2011), high parental aspirations are usually buffered by unfamiliarity with university level requirements, anxiety about affordability, and lack of awareness of financial aid opportunities. It can therefore be concluded that while high parental aspirations are necessary for increased educational attainment, this on its own is not sufficient in helping children attain higher levels of education.

Although a majority of mothers have high aspirations, the study also found that 1 in 4 mothers had aspirations below a degree with about 1 in 8 having aspirations for their children to only complete high school and below. Results point to a number of variables which might explain why some mothers have lower aspirations than others. Significant parental characteristics that affect aspiration are parental SES variables (education, job status, income), age, and household size. Consistent with Bourdieu's (1977a; 1986b) theory and its associated concepts, results from SES variables show that right from the preschool stage, mothers with higher education, income and job status hold significantly higher educational aspirations for their children than those from lower SES backgrounds. These results also show that there is a unique contribution from each of the of SES variables to maternal aspirations. An interesting finding regarding job status from the descriptive results is that parents who belonged to the category "small employers and own account workers", contrary 
to the general trend, held lower educational aspirations for their children compared to parents from other lower job status categories. A plausible explanation which warrants further investigation is that this group of parents, stemming from their own experiences, do not consider participation in higher education as a prerequisite for future success. They may also be influenced by the intention for their children to take over the running of their businesses sooner rather than later. The findings on SES are important because parental aspirations appear to be more important for children from socially disadvantaged backgrounds (Schoon et al. 2007). This will suggest that support for raising aspirations of parents from low SES backgrounds is an important step in improving the educational achievement of these children.

The above findings that, on the one hand, SES influences aspirations, and on the other, that parents from low SES backgrounds aspire for their children to attain higher levels of education than their own suggests a contradiction in Bourdieu's (1977b) concept of Habitus (that is, parents aspirations would be based on the 'statistical fate' of members of their social group). However, what this shows is that while parental habitus might influence their aspirations for their children's education, it is not entirely deterministic as originally conceptualised. Indeed Bourdieu (1990) later notes that the habitus is subject to change when circumstances of the individual or the environment changes. The implication is that, if parents can see that members of their community are able to progress through the educational ladder, or that there are mechanisms to support their children to move beyond the achievements of their social group, they will be inclined to set higher educational aspirations for their children. 
Results showing a positive relationship between maternal age and educational aspirations are consistent with the general trend of favourable educational outcomes for children with older mothers (Fergusson and Woodward 1999; Sutcliffe et al. 2012). Here, it is argued older mothers are those likely to delay childbirth in favour of career and educational ambitions, and are therefore more likely to be ambitious in their aspirations for their children. As hypothesised by the resource dilution theorists (Powell and Steelman 1995), mothers coming from larger households appear to attenuate their aspirations, taking into account the potential financial constraints of supporting their children through higher levels of education.

Concurrent with the transactional perspective child level characteristics had a significant influence on maternal aspirations. Significant predictors were birth order, gender and conduct problems. On the whole, parents appear to hold higher aspirations for first born children in comparison to other children in the birth order irrespective of family size. This positive effect of being first born has been highlighted in other educational as well as psychosocial domains (Booth and Kee 2009). The question is whether, this suggests "favouritism in the eyes of the beholder" or whether the impact of birth order is operating at an unconscious level. The most plausible explanation is an 'anchoring effect' (Tversky and Kahnemann 1974) whereby achievements of a first born child serve as an anchor to which aspirations for subsequent children are based. This constitutes an unconscious decision and parents need to be aware of this potential bias of child birth order.

Findings regarding gender were consistent with previous studies in the UK that mothers hold higher aspirations for girls than for boys (Schoon et al. 2007). While mothers may simply be reflecting the trends in higher education participation by the different genders in the UK, this 
has significant implications for closing the observed gender gap in achievement. Since aspirations do in fact influence subsequent participation, there may be a self-fulfilling prophecy whereby lowered aspirations for boys by their mothers result in lowered participation in higher education. The reason behind this differential maternal aspiration deserves further exploration.

The final significant child level predictor of maternal aspirations was conduct problems. As in previous studies (Rutchick et al. 2009), mothers in this study appeared to adjust their educational aspirations downward for children perceived as having behaviour problems. This can lead to a reinforcement of negative behaviours. For instance, if children with conduct problems become aware that their parents do not expect them to excel educationally, they are likely to adapt their behaviour to be consistent with this belief. This is because the parentchild relationships are internalised and carried forward by the child into subsequent interactions (LaFreniere and Dumas 1992). Parents of children with conduct problems might be assisted to understand that higher aspirations for the child could actually boost the child's self-confidence and reduce truant behaviour, rather than having low aspirations that reinforces such behaviours.

\subsection{Educational and Policy Implications}

It has been argued that teachers and other professionals often underestimate the educational aspirations of certain groups of parents such as those from socially disadvantaged communities, and not appreciate the importance with which they view education (e.g., Cummings et al. 2011; Goldenberg et al. 2001). Teachers also sometimes cite low parental educational aspirations as part of the explanation for generally low educational performance 
of children, particularly those from lower SES backgrounds (Holloway and Pimlott-Wilson 2011). Evidence from the current study suggests that most children's achievement is not constrained by low parental educational aspirations, and that the basis of the aforementioned beliefs by teachers is not entirely supported. A more plausible explanation for lower educational achievement is the inability of parents to translate their aspirations to reality. Thus, as part of a policy drive towards greater parental involvement, a first step will be for schools to discuss with parents their aspirations for their children's education. This will give teachers an insight into what the hopes of parents are for their children and using this as basis for exploring with parents what is required for bringing their aspirations to fruition for their children.

It is clear from the observed aspiration-participation gap discussed earlier that certain families need help to understand the prerequisites and pathways to higher education. Such families will benefit from outreach and clear information about the educational system and how to progress through it. Other interventions may include provision of role models, safe study environments and academically focused extracurricular activities for those children at risk of low academic performance (Gorard et al. 2012). In other words, there is a need for a policy shift in emphasis from raising aspirations to keeping aspirations on track (Cummings et al. 2011).

The findings from this study also suggest the need to utilise a multiple risks approach in identifying parents who need support in raising aspirations. This is because parental aspirations are stratified by multiple parental and child characteristics. For instance, a family that needs support in raising of aspirations is likely to be one where the mother comes from a 
low SES background with a large family, has a son who is lower in the birth order and with some conduct issues, rather than a family with only one of these characteristics. This is an example of a family which is at most risk and needing of support to increase the educational potential of their child. However, for such families lowered aspirations might be rooted in realistic anxieties about their capability to support their children to attain these goals (e.g., Bourdieu 1977b; Kirk et al. 2011; Schoon et al. 2007). Thus, increasing parental educational aspirations can only meaningfully occur within the context of helping them overcome their difficulties.

\subsection{Limitations}

In addition to those highlighted elsewhere within the discussion, the current study is limited by the fact that only maternal aspirations were explored. Like previous studies published in this area, aspirations of fathers were not considered. This is because the data came from main caregivers which often happen to be mothers. It may be interesting to contrast aspirations of both parents in the household in future research. Additionally, using secondary data means a need to reconceptualise and re-categorise certain variables in the data set. This is likely to influence the nature of findings. For instance, other researchers may come up with slightly different results if they choose a different approach and different categories from those used in the current study. Finally, it should be acknowledged that the predictors of maternal aspirations explored in the current study are by no means exhaustive and other determinants may exist.

\subsection{Conclusions}


To conclude, the current study extends the literature on parental educational aspirations in many ways. Firstly, it is one of the few existing studies that have explored the aspirations of mothers whose children are in preschool. Secondly, the study explored the influences of previously unexplored variables such as maternal age and birth order on maternal aspirations. These characteristics clearly have a significant influence on parental aspirations and should be taken into account in efforts to raise parental aspirations and subsequently children's educational achievement. Thirdly, findings from this study shed light on the unique factors that influence maternal aspirations by circumventing the confounding relationship between parental aspirations and children's academic performance. This is because children in the sample were just starting school and therefore had limited information about their previous academic achievements. Finally, the study is one of the first to adopt a theoretical framework that accounts for factors influencing maternal aspirations. In doing so, the study discussed the pathways through which these factors influence aspiration. This opens an opportunity for better targeting of interventions to raise parental aspiration and to assist the majority of parents to translate their aspirations into reality. It also opens up an opportunity for further research that evaluates these pathways of influence. 


\section{References}

Benner, A. D., \& Mistry, R. S. (2007). Congruence of mother and teacher educational expectations and low income youth's academic competence. Journal of Educational Psychology, 99(1), 140-153.

Booth, A., \& Kee, H. J. (2009). Birth order matters: The effect of family size and birth order on educational attainment. Journal of Population Economics, 22, 367-397.

Bourdieu, P. (1977a). Cultural reproduction and social reproduction. In J. Karabel and A. H. Halsey, (Eds.), Power and Ideology in Education (pp. 487-500). Oxford: Oxford University Press.

Bourdieu, P. (1977b). Outline of a theory of practice. Cambridge: Cambridge University Press.

Bourdieu, P. (1986a). Distinction: A social critique of the judgement of taste. London: Routledge \& Kegan Paul.

Bourdieu, P. (1986b). The forms of capital. In J. Richardson (Ed.), Handbook of theory and research for the sociology of education (pp. 241-258). Westport, CT: Greenwood Press.

Bourdieu, P. (1990). In other words: Essays towards a reflexive sociology. Cambridge: Polity Press.

Bourdieu, P., \& Passeron, J. C. (1990). Reproduction in education, society and culture. London: Sage.

Bradshaw, P., Marryat, L., Corbett, J., Ferrandon, M., \& Tipping, S. (2010). 'Growing Up in Scotland' sweep 4: 2008-2009 user guide. UK Data Archive Study, Number 5760.

Braveman, P. A., Cubbin C., Egerter S., Chideya, S., Marchi, K. S., Metzler, M., et al. 
(2005). Socioeconomic status in health research: One size does not fit all. JAMA, 294, 2879-2888.

Breen, R., \& Goldthorpe, J. H. (1997). Explaining educational differentials. Towards a formal Rational Action Theory. Rationality and Society, 9, 275-305.

Buchmann, C., \& Hannum, E. (2001). Education and stratification in developing countries: A review of theories and research. Annual Review of Sociology, 27, 77-102.

Chiapa, C., Garrido, J. L., \& Prina, S. (2012). The effect of social programs and exposure to professionals on the educational aspirations of the poor. Economics of Education Review, 31, 778-798.

Chowdry, H., Crawford, C., \& Goodman, A. (2010). Outcomes in the secondary school years: evidence from the Longitudinal Study of Young People in England. In A. Goodman \& P. Gregg (Eds.), Poorer children's educational attainment: How important are attitudes and behaviour? (pp. 34-43). York: Joseph Rowntree Foundation.

Cummings, C., Hall, E., Laing, K., Law, J., McLaughlin, J., Papps, I. et al. (2011). Can attitudes and aspirations help close the attainment gap? York: Joseph Rowntree Foundation.

Department for Children, Schools and Families (2007). The 'Children's Plan': Building brighter futures. Retrieved 15 January 2013, from http://webarchive.nationalarchives.gov.uk/20130401151715/https://www.education.g ov.uk/publications/eOrderingDownload/Childrens_Plan_Summary.pdf

Dika, S. L., \& Singh (2002). Applications of social capital in educational literature: A critical synthesis. Review of Educational Research, 72(1), 31-60.

DiMaggio, P. (1979). Review essay: On Pierre Bourdieu. American Journal of Sociology, 
84(6), 1460-1474.

Englund, M. M., Luckner, A. E., Whaley, G. L. J., \& Egeland, B. (2004). Children's achievement in early elementary school: Longitudinal effects of parental involvement, expectations, and quality of assistance. Journal of Educational Psychology, 96(4), $723-730$.

Esping-Andersen, G. (2004). Untying the Gordian knot of social inheritance. Research in Social Stratification, 21, 115-138.

Fan, X., \& Chen, M. (2001). Parental involvement and students' academic achievement: A meta-analysis. Educational Psychology Review, 13(1), 1-22.

Fanti, K. A., Henrich, C. C., Kathryn, A. Brookmeyer, K. A., \& Kuperminc, G. P. (2008). Toward a Transactional Model of parent-adolescent relationship quality and adolescent psychological adjustment. The Journal of Early Adolescence, DOI: $10.1177 / 0272431607312766$

Fergusson, D. M., \& Woodward, L. J. (1999). Maternal age and educational and psychosocial outcomes in early adulthood. Journal of Child Psychology and Psychiatry, 43(3), $479-489$.

Gini, G. (2008). Association between bullying behaviour, psychosomatic complaints, emotional and behavioural problems. Journal of Paediatrics and Child Health, 44, $492-497$.

Goldenberg, C., Gallimore, R., Reese, L., \& Garnier, H. (2001). Cause or effect? A longitudinal study of immigrant Latino parents' aspirations and expectations, and their children's school performance. American Educational Research Journal, 38(3), $547-582$.

Goodman, R. (1997). The Strengths and Difficulties Questionnaire: A research note. Journal 
of Child Psychology and Psychiatry. 38(5), 581-586.

Gorard, S., See, B. H., \& Davies, P. (2012). The impact of attitudes and aspirations on educational attainment and participation. York: The Joseph Rowntree Foundation.

Gregg, P., \& Washbrook, E. (2009). The socioeconomic gradient in child outcomes: The role of attitudes, behaviours and beliefs. The primary school years. Report for the Joseph Rowntree Foundation. Bristol: Centre for Market and Public Organisation, University of Bristol.

Holloway, S. L., \& Pimlott-Wilson, H. (2011). The politics of aspiration: Neo-liberal education policy, 'low' parental aspirations, and primary school Extended Services in disadvantaged communities. Children's Geographies, 9(1), 79-94.

Jeynes, W. H. (2007). The relationship between parental involvement and urban secondary school student academic achievement: A meta-analysis. Urban Education, 42(1), 82110.

Juang, L. P., \& Silbereisen, R. K. (2002). The relationship between adolescent academic capability beliefs, parenting and school grades. Journal of Adolescence, 25, 3-18.

Kirk, C. M., Lewis-Moss. R. K., Nilsen, C., \& Colvin, D. Q. (2011). The role of parent expectations on adolescent educational aspiration. Educational Studies, 37(1), 89-99.

LaFreniere, P. J., \& Dumas, J. E. (1992). A transactional analysis of early childhood anxiety and social withdrawal. Development and Psychopathology, 4, 385-402.

Lee, K. S. (2010). Parental educational investments and aspirations in Japan. Journal of Family Issues, 31(12), 1579-1603.

Long, D. J., Burt, K. B., Obradovic, J. Riley, J. R., Boelcke-Stennes, K., \& Tellegen, A. (2005). Developmental cascades: linking academic achievement and externalising and internalising symptoms over 20 years. Developmental Psychology, 41(5), 733-746. 
Masten, A. S., Roisman, G. I., Long, D. J., Burt, K. B., Obradovic, J. Riley, J. R., et al. (2005). Developmental cascades: linking academic achievement and externalising and internalising symptoms over 20 years. Developmental Psychology, 41(5), 733-746.

McLeod, J. D. and Kaiser, K. (2004). Childhood emotional and behavioural problems and educational attainment. American Sociological Review, 69, 636-658.

Nash, R. (1990). Bourdieu on education and social and cultural reproduction. British Journal of Sociology of Education, 11(4), 431-447.

Office for National Statistics (2005). National statistics socio-economic classification user manual. Hampshire: Pelgrave Macmillan.

Oketch, M., Mutisya. M., \& Sagwe, J. (2012). Parental aspirations for their children’s educational attainment and the realisation of universal primary education (UPE) in Kenya: Evidence from slum and non-slum residences. International Journal of Educational Development, 32, 764-772.

Pettit, G., Laird, R., Dodge, K., Bates, J., \& Criss, M. (2001). Antecedents and behaviour problem outcomes of parental monitoring and psychological control in early adolescence. Child Development, 72, 583-598.

Pomerantz, E. M., \& Eaton, M. M. (2001). Maternal intrusive support in the academic context: Transactional socialization processes. Developmental Psychology, 37, 174186.

Powell, B., \& Steelman, L. C. (1995). Feeling the pinch: Child spacing and constraints on parental economic investments in children. Social Forces, 73, 1465-1486.

Price, J. (2008). Parent-child quality time: Does birth order matter? Journal of Human Resources, 43(1), 240-265.

Raleigh, E., \& Kao, G. (2010). Do immigrant minority parents have more consistent college 
aspirations for their children? Social Science Quarterly, 91, 1083-1102.

Räty, H. (2003). The significance of parents' evaluations of their own school for their educational attitudes. Social Psychology of Education, 6, 43-60.

Reynolds, J. R., \& Pemberton, J. (2001). Rising college expectations among youth in the United States: A comparison of the 1979 and 1997 NLSY. Journal of Human Resources, 36, 703-26.

Rutchick, A. M., Smyth, J. M., Lopoo, L. M., \& Dusek, J. B. (2009). Great expectations: The biasing effects of reported child behavior problems on educational expectancies and subsequent academic achievement. Journal of Social and Clinical Psychology, 28(3), $392-413$.

Sameroff, A. (Ed.) (2009). The transactional model of development: How children and contexts shape each other. Washington, DC: American Psychological Association.

Sameroff, A. J., \& Mackenzie, M. J. (2003). Research strategies for capturing transactional models of development: The limits of the possible. Development and Psychopathology, 15, 613-640.

Schoon, I., Martin, P., \& Ross, A. (2007). Career transitions in times of social change. His and her story. Journal of Vocational Behaviour, 70(1), 78-96.

Scottish Executive (2006). Scottish schools (parental involvement) act 2006: Guidance. Edinburgh: Scottish Executive.

Scottish Funding Council (2013). Learning for All: Seventh update report on measures of success 2013. Retrieved 2 June, 2013, from http://www.sfc.ac.uk/web/FILES/Access/2013_LFA_full_report.pdf

Spera, C. (2006). Adolescents' perceptions of parental goals, practices, and styles in relation to their motivation and achievement. Journal of Early Adolescence, 26, 456-490. 
Spera, C., Wentzel, K. R., \& Matto, H. C. (2009). Parental aspirations for their children's educational attainment: Relations to ethnicity, parental education, children's academic performance, and parental perceptions of school climate. Journal of Youth Adolescence, 38, 1140-1152.

Sullivan, A. (2002). Bourdieu and education: How useful is Bourdieu's theory for researchers? The Netherland's Journal of Social Sciences, 38(2), 144 -166.

Sutcliffe, A. G., Barnes, J., Belsky, J., Gardiner, J., \& Melhuish, E. (2012). The health and development of children born to older mothers in the United Kingdom: Observational study using longitudinal cohort data. British Medical Journal, 345:e5116.

Sutherland, K. S., \& Oswald, D. P. (2005). The relationship between teacher and student behavior in classrooms for students with emotional and behavioral disorders: Transactional processes. Journal of Child and Family Studies, 14(1), 1-14.

Sy, S. R., \& Schulenberg, J. E. (2005). Parent beliefs and children's achievement trajectories during the transition to school in Asian American and European American families. International Journal of Behavioral Development, 29(6), 505-515.

Theule J., Wiener J., Tannock R., \& Jenkins J. M. (2013). Parenting stress in families with children with ADHD: A meta-analysis. Journal of Emotional and Behavioral Disorders, 21(1), 3-17.

Tversky, A., \& Kahneman, D. (1974). Judgment under uncertainty: Heuristics and biases. Science, 185, 1124-1130.

Villiger, C., Wandeler, C., \& Niggli, A. (2014). Explaining differences in reading motivation between immigrant and native students: The role of parental involvement. International Journal of Educational Research, 64, 12-25.

Vryonides, M., \& Gouvias, D. (2012). Parents' aspirations for their children's educational 
and occupational prospects in Greece: The role of social class. International Journal of Educational Research, 53, 319-329.

Wentzel, K. R. (1998). Parents' aspirations for children's educational attainments: Relations to parental beliefs and social address variables. Merrill-Palmer Quarterly, 44, 20-37. Yamamoto, Y., \& Holloway, S. D. (2010). Parental expectations and children's academic performance in sociocultural context. Educational Psychology Review, 22, 189-214.

Zhang, Y., Kao, G., \& Hannum, E. C. (2007). Do mothers in rural China practice gender equality in educational aspirations for their children? Comparative Education Review, $51(2), 131-157$. 


\section{List of Tables}

Table 1: Descriptive and bivariate association between maternal aspirations and selected parental and child variables $(\mathrm{N}=1999)$

\begin{tabular}{lccc}
\hline Predictors & & \multicolumn{2}{c}{ Maternal Aspirations (\%) } \\
\hline & High school and & College & University and $p$ value \\
below & & above \\
& $N=238(12.4 \%)$ & $N=268(13.6 \%)$ & $N=1493(74 \%)$
\end{tabular}

\section{Parental Variables}

Socioeconomic Status

Mothers Job status

Never worked (52)

Semi-routine and routine (555)

Lower supervisory and technical (116)

Small employers and own account

workers (112)

Intermediate (379)

Managerial and professional (784)

Household Income ${ }^{1}$ (1999)

Mothers education

No qualification (143)

High school and below (430)

Vocational (767)

Degree (654)
16.2

17.8

13.6

20.6

11.6

6.3

$9[20,000-$

22,999]

$10[23,000-$

25,999]

$12[29,000-$

31,999]

68.9

63.1

69.6

63.6

73.8

86.5

$\begin{array}{ll}7.2 & 86.5\end{array}$

.000

$\begin{array}{lll}24.1 & 18.8 & 57.1 \\ 16.8 & 19.1 & 64.1 \\ 12.3 & 71.8 \\ 5.5 & 15.9 & 89.6\end{array}$




$\begin{array}{cccc}20-29(323) & 14.7 & 16.1 & 69.2 \\ 30-39(1110) & 12.9 & 14.1 & 73.0 \\ 40 \text { and above (566) } & 9.4 & 10.0 & 4.0 .6 \\ \text { Family Size } e^{2}(1865) & 4.26 & 4.17\end{array}$

69.2

3.0

0.6

\section{Child Variables}

Emotional and behavioural difficulties

$$
\begin{aligned}
& \text { Conduct problems }^{2} \text { (1990) } \\
& \text { Emotional symptoms }^{2} \text { (1988) } \\
& \text { Hyperactivity/inattention }{ }^{2} \text { (1985) } \\
& \text { Peer problems }{ }^{2} \text { (1984) } \\
& \text { Pro-social behaviour }^{2} \text { (1989) }
\end{aligned}
$$

Birth order

First born (912)

Other child (1087)

Gender

Female (992)

Male (1007)
2.21

1.59

3.72

1.42

8.10

9.1

15.3

11.8

12.9
2.03

1.63

3.89

1.34

8.19

1.59

.000

1.31

3.26

1.07

8.38

.018

.001

.02

NB: Percentages are based on weighted data; $\mathrm{N}$ values (in bracket) are based on un-weighted data; Differences between the total sample and sample size for each variable represents missing data.

Household income, household size, and emotional and behavioural variables analysed using ANOVA. All other variables analysed using chi-square.

${ }^{1}$ Household income measured on a scale of 1-17 (1- less than $£ 3,999 ; 17-56,000$ or more). Values in bracket represent the average household income band.

${ }^{2}$ The values represent averages (Mean) and NOT percentages. 
Table 2: Ordered logistic regression coefficients for parental and child variables as predictors of maternal aspirations for their children education

\begin{tabular}{llllll}
\hline Predictors & $B$ & $S E$ & Wald & Odds Ratio & \% likelihood
\end{tabular}

Parental Variables

Socioeconomic Status

$\begin{array}{lccccc}\text { Mothers education } & .42 & .07 & 36.34^{* * *} & 1.52 & 52.19 \\ \text { Income } & .04 & .02 & 5.24^{*} & 1.04 & 4.08 \\ \text { Mothers job status } & .10 & .04 & 6.78^{* *} & 1.11 & 10.52\end{array}$

Mothers age

$\begin{array}{lccccc}20-29 & -.19 & .19 & 1.05^{\mathrm{ns}} & 0.83 & -17.30 \\ 30-39 & -.38 & .14 & 6.99^{* *} & 0.68 & -31.61 \\ 40 \text { and above } & - & - & - & & \\ \text { Household Size } & -.12 & .06 & 4.78^{* *} & 0.89 & -11.31\end{array}$

\section{Child Variables}

Emotional and Behavioural difficulties

$\begin{array}{lccccc}\text { Conduct problems } & -.12 & .05 & 7.38^{* *} & 0.89 & -11.31 \\ \text { Emotional symptoms } & .00 & .04 & .01^{\mathrm{ns}} & 0.99 & 0.39 \\ \text { Hyperactivity/inattention } & .02 & .03 & .28^{\mathrm{ns}} & 1.02 & 2.02 \\ \text { Peer problems } & -.04 & .04 & .72^{\mathrm{ns}} & 0.96 & -3.92 \\ \text { Pro-social behaviour } & .00 & .04 & .00^{\mathrm{ns}} & 1.00 & 1.00\end{array}$

Birth order

First born

$\begin{array}{lllll}.40 & .13 & 9.65^{* *} & 1.49 & 49.18\end{array}$

Other child

Gender

Female

.23

.11

$4.25 *$

1.25

25.86 
Male

$* * * \mathrm{p}<.001 ; * * \mathrm{p}<.01 ;{ }^{*} \mathrm{p}<.05$ 